\title{
PENETAPAN RETENTION TIME PROGESTERON DALAM PELARUT ELUEN PHASE MOBILE MENGGUNAKAN HIGH PERFORMANCE LIQUID CHROMATOGRAPHY
}

\section{DETERMINATION RETENTION TIME OF PROGESTERON ON ELUEN PHASE MOBILE SOLUTIONS USING HIGH PERFORMANCE LIQOUID CHROMATOGRAPHY}

\author{
Evania Haris Chandra 1), M. Lazuardi 2), Suryanie Sarudji 2), Lilik Maslachah 2), \\ M. Sukmanadi 2), Suzanita Utama ${ }^{2)}$ \\ 1) Mahasiswa, 2) Dosen \\ Fakultas Kedokteran Hewan Universitas Airlangga \\ Kampus C UNAIR, Jl. Mulyorejo-Surabaya 60115 \\ Telp. 031-5992785, Fax. 031-5993015 \\ Email: jbmvunair@gmail.com
}

\begin{abstract}
The aim of this research was to determine the level of stability of Progesterone-retention time on Eluen Phase Mobile (EPM) solution in storage period for six, eight and 12 hours using High Performance Liquid Chromatography (HPLC). The research method used posttest-only control group design by using three treatments and six repetitions. The three repetitions consist into six hours, eight hours and 12 hours. The data were obtained analyzed by Summery Independent T-Test with SPSS 24 for windows. The results showed that the progesterone treatment in EPM solvents with six-hour storage (P1) and eight hours (P2) retention time progesterone are stable but the progesterone treatment in EPM solvent with 12-hour storage (P3) showed an unstable due to storage time. Besides that there are irrelevant peak which show that many pure molecular fractions are separated in the stationary phase so that the molecular structure of the substance begins to break down. Based on these results, it can be concluded that the storage time of Progesterone in Eluen Phase Mobile began to be unstable at 12 hours of storage.
\end{abstract}

Key words: Stability, Progesteron, retention time, High Performance Liquid Chromatography (HPLC)

\section{PENDAHULUAN}

Progesteron adalah hormon steroid yang disintesis terutama di ovarium, plasenta dan kelenjar adrenal (Graham JD et al., 1997; Sinreih M et al., 2015). Progesteron banyak digunakan untuk terapi hormon oleh karena itu perlu dibentuk metode yang sederhana dan akurat untuk identifikasi dan penentuan kuantitatif dalam obatobatan (Maliwal et al., 2009). Banyak upaya telah dilakukan untuk mendeteksi steroid diantaranya metode Thin Layer Chromatography (TLC) sederhana telah digunakan untuk analisis kualitatif, immunoassay untuk kuantifikasi, Gas Chromatography (GC) untuk analitik. Metode yang cepat, akurat untuk analisis kualitatif dan kuantitatif estriol, estradiol-17 beta, estrone, testosteron, dan progesteron yaitu dengan High Performance Liquid Chromatography (HPLC) (Erkoc F et al., 1989).

High Performance Liquid Chromatography (HPLC) merupakan perangkat baca berbasis kromatografi. Kromatografi merupakan teknik pemisahan yang paling umum dan paling sering digunakan dalam bidang kimia analisis (Gandjar dan Rohman, 2014). Analisis menggunakan metode 
HPLC memiliki beberapa kelebihan yaitu waktu analisis cepat, resolusi dan sensitivitas tinggi serta dapat dihubungkan dengan bermacam-macam detector, diantaranya UV/VIS detektor, fluorescence detector, conductivity detector, refraktif index, Evaporative Light Scattering (ELSD), electrochemical detector dan Mass Spectrometry detector (De Lux, 2004; Suprianto, 2014).

Prinsip dasar kromatografi adalah molekul tidak hanya larut dalam cairan tetapi juga dapat melarutkan atau berinteraksi dengan sediaan padat. Molekul yang dilarutkan dalam cairan dilewatkan ke dalam kolom partikel padat, yang bisa berinteraksi akan bergerak lebih lambat dari pada pelarut dan membutuhkan beberapa waktu untuk dilarutkan dalam cairan (Bird, 1989). Terdapat beberapa hal yang dapat mempengaruhi stabilitas obat dari sediaan farmasi diantaranya adalah interaksi bahan aktif dengan bahan aktif lainnya, faktor lingkungan seperti temperatur, faktor formulasi seperti $\mathrm{pH}$ dan sifat pelarut (David B. Troy, 2006; USP.30; Sabdowati, 2015). Ketika obat (bahan aktif) masuk dalam pelarut struktur molekul dari obat tersebut terbuka oleh sebab itu obat tersebut memiliki masa peruraian ketahanan tertentu sehingga memiliki keterbatasan. Keterbatasan tersebut adalah batas standar, maka perlu dilakukan penelitian terhadap Progesteron supaya dapat mengetahui daerah paling stabil dalam daerah yang beresiko tidak stabil. Daerah yang paling stabil tersebut digambarkan dalam bentuk waktu tambat kromatogram atau retention time (Nuriyazizah, 2018).

Retention time atau waktu tambat adalah selang waktu yang dibutuhkan oleh analit mulai saat injeksi sampai keluar dari kolom dan sinyalnya secara maksimal ditangkap oleh detektor, yang diukur pada puncak maksimum kromatogram (Susanti dan Dachriyanusus, 2014). Proses pemeriksaan dimulai dengan teknik pemisahan kemudian dibaca dengan integrator dan terdapat titik kritis, pada titik kritis tersebut ada kesempatan untuk menganalisis daerah batas antara yang stabil dan tidak stabil yang sampai saat ini persoalan ini belum terselesaikan.

Tujuan dari uji stabilitas untuk mengetahui ketahanan suatu produk sesuai dengan batas-batas tertentu selama penyimpanan dan penggunaannya atau umur simpan suatu produk yang masih mempunyai sifat dan karakteristik yang sama seperti waktu pembuatan (David B. Troy, Paul Beringer, 2006; Sabdowati, 2015). Pemeriksaan stabilitas menggunakan HPLC membutuhkan fase gerak dimana pemilihan fase gerak (pelarut) dapat ditentukan melalui eksperimen trial and error hingga didapatkan kromatogram yang diinginkan (Dong, 2006). Beberapa penelitian menggunaan kombinasi fase gerak (pelarut) yaitu fase organik seperti asetonitril, methanol dan dapar seperti dapar asetat, dapar fosfat, tetrahidrofuran (THF) digunakan dalam sistem HPLC. Komposisi fase gerak menentukan pemisahan zat dan seringkali komposisi yang tidak tepat memberikan hasil yang buruk walaupun sebenarnya kombinasi fase gerak yang digunakan sudah benar (Aulia dkk, 2017). Obat golongan hormonal memiliki ciri tidak tahan pada pelarut tertentu, jadi metode pemeriksaan kestabilan disesuaikan dengan masa stabilitas obat dalam pelarut.

Pada penelitian ini digunakan bahan aktif Progesteron sebagai subjek penelitian terhadap stabilitas waktu tambat dan EPM (fase gerak) yang terdiri dari Water pro HPLC: Metanol pro HPLC 3:7 sesuai penelitian progesterone like-effect sebelumnya yang dilakukan oleh Lazuardi dan Bambang (2017) dengan panjang gelombang $254 \mathrm{~nm}$. Kelebihan methanol digunakan untuk analisis steroid yaitu bersifat universal 
sehingga dapat melarutkan analit yang bersifat polar dan nonpolar; dapat menarik alkaloid, steroid (Astarina, dkk., 2013). Pengujian stabilitas progesteron dalam pelarut Eluen Phase Mobile (EPM) dengan alat HPLC dilakukan dengan lama penyimpanan yang berbeda yaitu enam, delapan dan 12 jam.

\section{MATERI DAN METODE PENELITIAN}

Alat dan Bahan

Alat yang digunakan dalam penelitian ini adalah Kromatografi Cair Kinerja Tinggi (Shimadzu) yang terdiri dari: pompa (LC-6AD), kolom

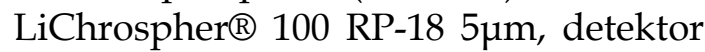
Photo Diode Array (PDA) SPD-M20A UVVisible, degasser DGU-20A5, communication bus module CBM-20A, fraction collector FRC-10A, program computer PC. $\mathrm{pH}$ meter (MachereyNagel), vortex, microcup, labu ukur, mikropipet dan tip, gelas ukur, hairdryer, satu buah microsyringe.

Bahan yang digunakan dalam penelitian ini adalah Standar Progesteron, Water pro HPLC (Merck), Water pro Injeksi, Methanol grade for chromatography (Merck), Aquadest.

\section{Pembuatan Larutan Induk Progesteron}

Pembuatan larutan induk progesteron dimulai dengan penimbangan progesteron (crm) sebanyak $5 \mathrm{mg}$ dilarutkan dalam Eluen Phase Mobile (Water pro HPLC: Metanol pro HPLC 3:7) sebanyak 0,5 $\mathrm{ml}$ selanjutnya divortex. Larutan Induk diencerkan menjadi 20 ppm disimpan di dalam ruang pendingin bedasarkan tiga perlakuan yaitu enam, delapan dan 12 jam.

\section{Penentuan Panjang Gelombang}

Spektrum progesteron diatur pada panjang gelombang $254 \mathrm{~nm}$ menggunakan Spektrofotometer $U V$ Visible.

\section{Optimasi}

Eluen Phase Mobile (EPM) dibuat dan diinjeksi menggunakan injektor rheodyne universal dengan volume injeksi $40 \mu \mathrm{L}$ kemudian dilihat dan dalam gerbang suntik dua kali kapasitas gerbang suntik. Hasil waktu tambat Progesteron diperhatikan kromatogram pengganggu lainnya di depan atau di belakang analit. Nilai alfa (selektifitas) yang ditentukan tidak boleh sama dengan satu.

\section{Analisis Data}

Data berupa kuantitatif hasil waktu tambat kromatogram dianalisis menggunakan Summery Independent Sample T-Test dalam aplikasi SPSS 24 for windows (Statistical Programs for Social Scientific).

\section{HASIL DAN PEMBAHASAN}

\begin{tabular}{|c|c|}
\hline $\begin{array}{c}\text { Lama waktu } \\
\text { penyimpanan }\end{array}$ & Mean \pm SD \\
\hline P1 & $13.3 \pm 0.6$ \\
\hline P2 & $13.4 \pm 0.2$ \\
\hline P3 & $13.2 \pm 0.7$ \\
\hline
\end{tabular}

Tabel 4.1 Jumlah rata-rata retention time Progesteron (crm) yang dilarutkan EPM dalam waktu penyimpanan enam, delapan dan 12 jam yang diinjeksi pada HPLC.

Hasil dari sampel Progesteron dalam pelarut EPM pada penyimpanan enam jam dan delapan jam dengan enam pengulangan dianalisis dengan Summery Indpendent Sample T-Test menunjukkan nilai Sig.(2-tailed) $0.877>0.05$ tidak terdapat perbedaan yang berarti pada enam jam dan delapan jam masih menunjukkan 
kestabilan sesuai dengan penyuntikan kontrol Progesteron (crm). Hasil dari sampel Progesteron dalam pelarut EPM pada penyimpanan 12 jam dengan enam pengulangan, dianalisis dengan Summery Independent Sample T-Test menunjukkan nilai Sig.(2-tailed) $0.717>0.05$ tidak terdapat perbedaan yang menunjukkan kestabilan namun pada uji sebenarnya pada kelompok 12 jam dengan enam pengulangan terdapat lima titik yang stabil yaitu \pm menit ke 12 , 13 dan terdapat satu titik yang menunjukkan mulai tidak stabil yaitu \pm menit ke 14.
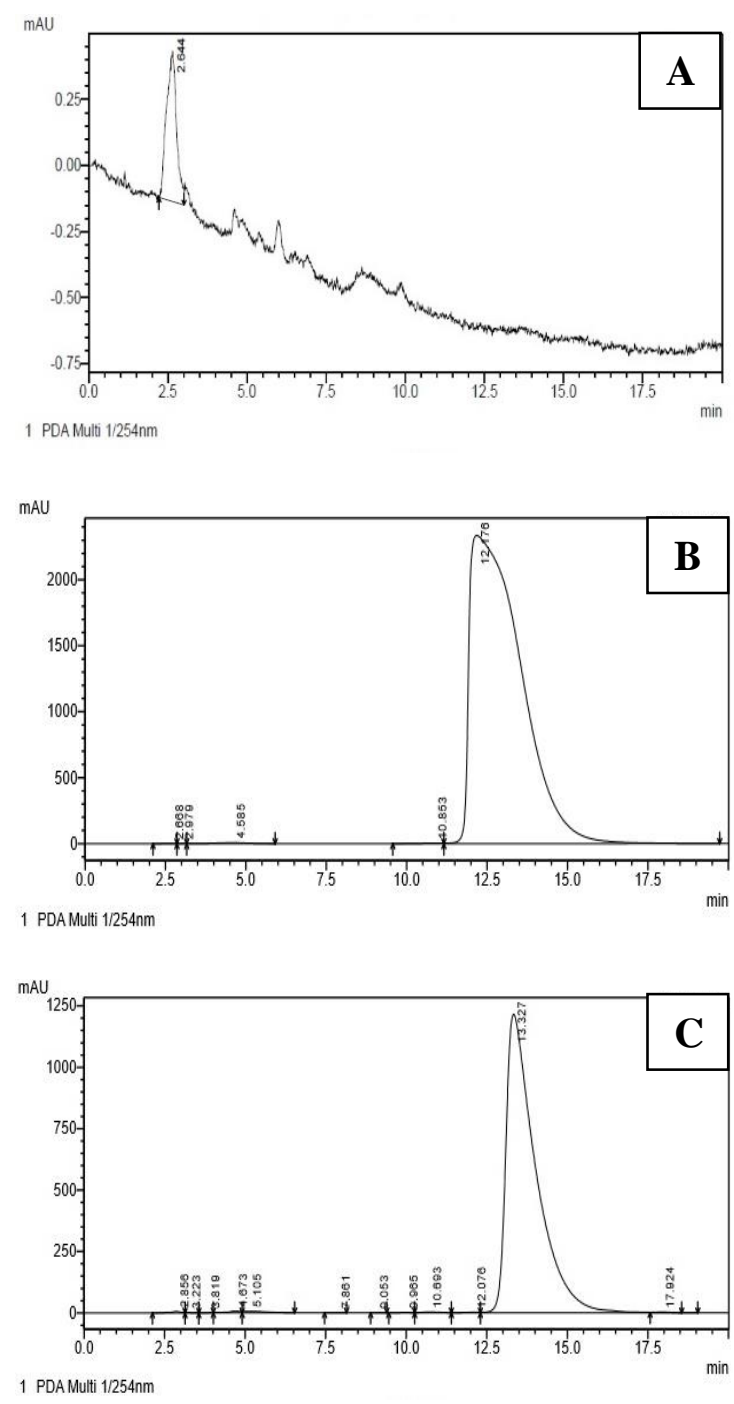

Gambar 1. Hasil Kromatogram: (A) Kontrol Penyuntikan larutan EPM, (B) dan (C) Kontrol Progesteron (crm) dalam pelarut EPM tanpa waktu penyimpanan.
Gambar 1(A) menunjukkan Perlakuan kontrol Eluen Phase Mobile tidak menunjukkan adanya puncak waktu tambat karena Eluen Phase Mobile merupakan fase gerak (Mobile) sehingga tidak boleh ada puncak waktu tambat. Apabila ada puncak waktu tambat pada saat Eluen Phase Mobile diinjeksikan berarti dalam proses pembersihan kolom tersebut kurang bersih atau dalam pembuatan larutan Eluen Phase Mobile (fase gerak) terkontaminasi dengan larutan lain. Pada menit ke dua merupakan gambaran mulai masuknya sampel kontrol pelarut

Eluen Phase Mobile ke dalam gerbang suntik (Rheodyn) yang berarti pada saat itu juga terjadi proses adsorbs-partisi oleh kolom analitik. Daerah analit puncak impurity pengotor pada menit ke dua mendapatkan resolusi a (alfa) dari metode yang digunakan sangat sempurna yang berarti $a \neq 1$. Pada perlakuan kontrol Progesteron (crm) tanpa waktu lama penyimpanan menunjukkan puncak waktu tambat \pm pada menit ke 12 (Gambar 1B) dan 13 (Gambar 1C) yang menyatakan Progesteron masih stabil pada waktu tersebut.
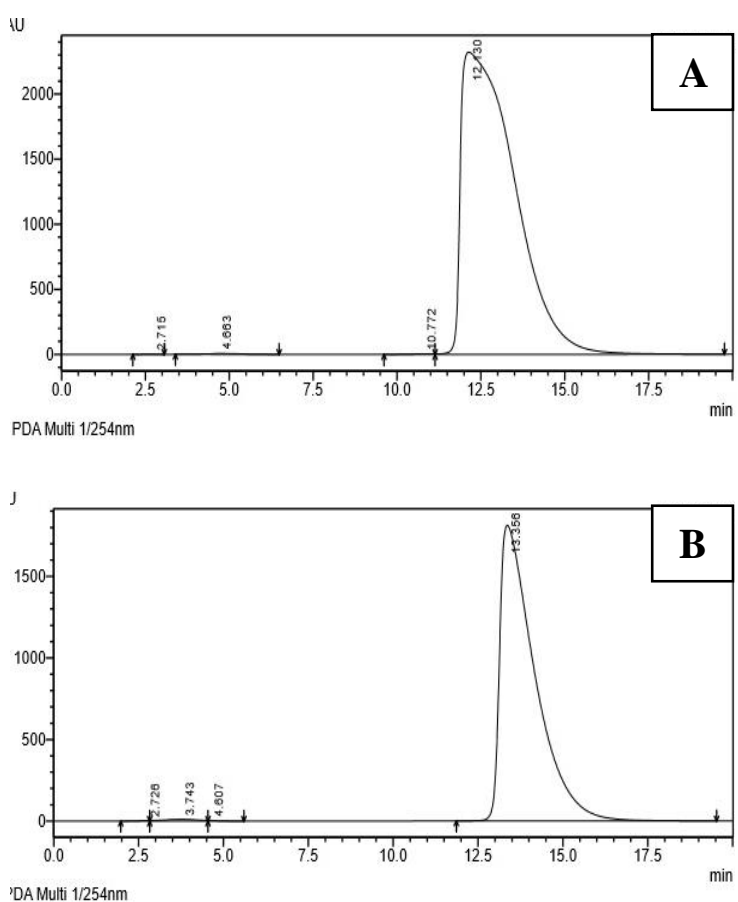

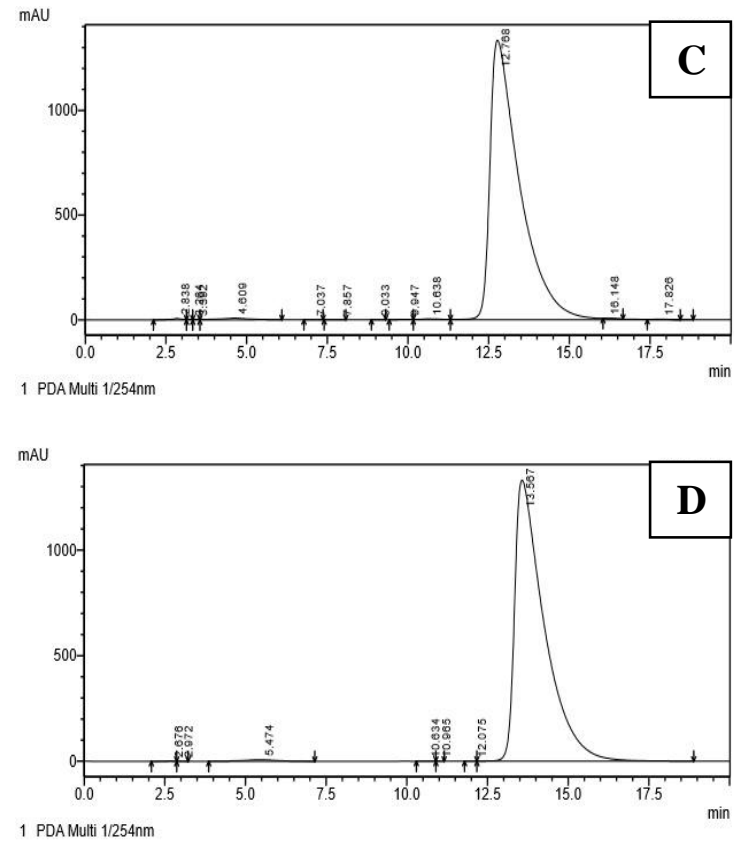

Gambar 2. Hasil Kromatogram (A) dan (B) Progesteron (crm) terlarut dalam EPM selama enam jam. (C) dan (D) Progesteron $(\mathrm{crm})$ terlarut dalam EPM selama delapan jam dengan HPLC, kecepatan alir $0,5 \mathrm{ml} /$ menit, $\lambda=254 \mathrm{~nm}$, menggunakan kolom ODS/C-18

Pada perlakuan enam jam menujukkan puncak waktu tambat pada menit ke 12 sejumlah satu (Gambar 2A) dan pada menit ke 13 sejumlah lima (Gambar 2B) dan perlakuan delapan jam menunjukkan puncak waktu tambat pada menit ke 12 sejumlah satu (Gambar 2C) dan pada menit ke 13 sejumlah lima (Gambar 2D) sesuai puncak kromatagram yang muncul pada penyuntikan kontrol progesteron yang berarti progesteron dalam pelarut Eluen Phase Mobile masih stabil pada penyimpanan tersebut. Hal ini sesuai dengan penelitian yang dilakukan oleh Lazuardi dan Bambang (2018) standar efek progesteron diperoleh dalam waktu retensi sekitar 6,44 menit pada preparatt medroksi progesteron asetat, dan 8,801 menit pada preparat megestrol asetat, dan 11 sampai 12 menit pada preparat progesteron.
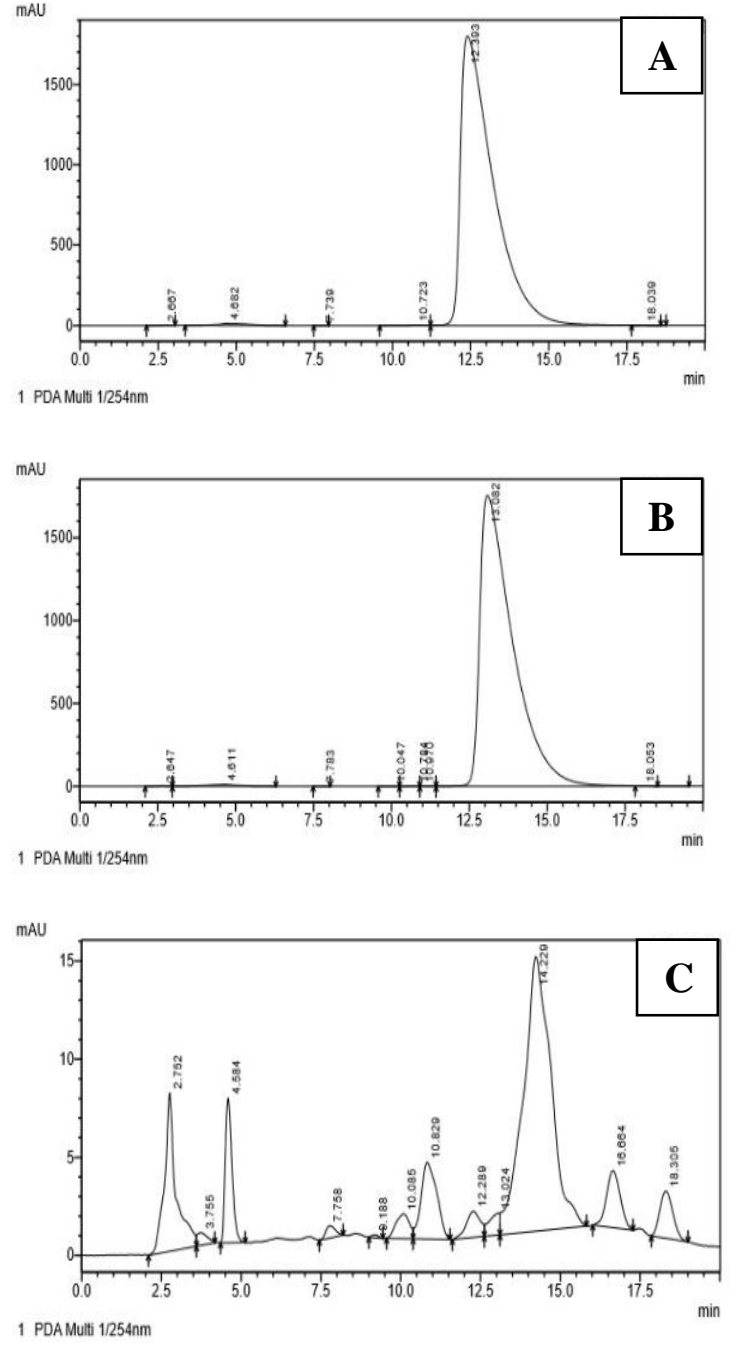

Gambar 3. Hasil Kromatogram (A) dan (B) Progesteron (crm) terlarut dalam EPM selama 12 jam yang stabil. (C) Progesteron $(\mathrm{crm})$ terlarut dalam EPM selama 12 jam yang tidak stabil dengan HPLC, kecepatan alir $0,5 \mathrm{ml} /$ menit, $\lambda=254 \mathrm{~nm}$, menggunakan kolom ODS/C-18

Pada perlakuan interval waktu penyimpanan 12 jam terdapat enam pengulangan yang terdiri dari lima stabil (Gambar 3A dan 3B) dan satu tidak stabil (Gambar 3C). Hal tersebut menunjukkan bahwa progesteron pada penyimpanan 12 jam menunjukkan mulai tidak stabil dikarenakan lamanya waktu penyimpanan Progesteron yang dilarutkan dalam Eluen Phase Mobile. 
Disamping itu terdapat irrelevan peak yang muncul, banyak fraksi molekul murni yang terpisah pada fase diam sehingga struktur molekul zat mulai rusak atau pecah. Prinsip adsorpsi-partisi tidak sempurna pada jarak waktu 12 jam karena kemampuan mengikat fase diam tidak bisa seluruhnya mengikat Progesteron semua yang sudah terlalu lama dalam pelarut Eluen Phase Mobile.

Hal ini sesuai dengan pernyataan Osol et al (1980) yang menyebutkan bahwa banyak faktor yang mempengaruhi stabilitas dari sediaan farmasi, antara lain stabilitas bahan aktif, interaksi antara bahan aktif dengan bahan tambahan, proses pembuatan bentuk sediaan, kemasan, cara pengemasan dan kondisi lingkungan yang dialami selama pengiriman, penyimpanan, penanganan dan jarak waktu antara pembuatan dan penggunaan. Faktor lingkungan seperti temperatur, radiasi cahaya dan udara (khususnya oksigen, karbon dioksida dan uap air) juga mempengaruhi stabilitas. Demikian pula faktor formulasi seperti ukuran partikel, $\mathrm{pH}$, sifat dari air dan sifat pelarutnya dapat mempengaruhi stabilitas.

Bahan aktif progesteron dengan struktur molekul yang mengandung cincin aromatik majemuk diketahui memiliki ikatan kuat yang sulit terputus, maka diperlukan energi yang tinggi untuk memutusnya, namun progesteron terikat dengan gugus $\mathrm{O}$ dan $\mathrm{H}^{+}$yang akhirnya menurunkan kekuatan ikatan aromatik tersebut. Apabila molekul terlarut sempurna dengan Eluen Phase Mobile maka resiko putus ikatan akan makin tinggi. Hal itu disebabkan ikatan $\mathrm{O}$ paling ujung akan terikat dengan gugus positif dari pelarutnya sehingga senyawa ini bila disimpan dalam EPM lebih dari 12 jam akan terpisah akibat proses partisi dari kolom, maka akan muncul anak-anak kromatogram. Ikatan yang paling memungkinkan bertahan adalah antara enam dan delapan jam, disebabkan faktor daya tarik menarik ujung $\mathrm{O}$ masih belum begitu kuat dibanding dengan energi resonansi dari aromatik majemuk. Diketahui pula bagian-bagian dari aromatic majemuk ini diikat dengan gugus $\mathrm{H}$. Gugus $\mathrm{H}$ merupakan proton donor (gugus positif: mendorong) sementara proton donor dalam struktur progesteron tidak sebanding kekuatan energi dengan gugus penarik elektron (atom $\mathrm{O}$ ), maka dalam waktu 12 jam kekuatan ikatan $\mathrm{O}$ akan lebih kuat dari proton $\mathrm{H}$ yang menyebabkan ikatan terputus (Lazuardi dan Bambang, 2017).

Apabila struktur progesteron yang putus diinjekkan dalam kolom maka ada tiga kemungkinan: (1) seluruh molekul yang ada tidak bisa terpantau sehingga tidak memunculkan kromtogram, (2) struktur molekul terpantau tapi area jadi kecil karena cincin inti saja yang terpantau, (3) semua terpantau dan pecahan anak akan muncul. Sementara diketahui bahwa fase diam memiliki kejenuhan waktu tertentu, dengan arti bahwa kemampuan dia mengikat analit berbanding lurus dengan kemampuan permukaan oktadesilsilan (ODS/C18) menangkap analit itu. Apabila struktur yang sudah tidak stabil diinjekkan dalam kolom yang sudah jenuh maka resiko ketigalah yang akan muncul, untuk menghindari hal tersebut dilakukan (1) system suitability testing (SST) dengan cara menyuntikkan Eluen Phase Mobile tiga kali pada HPLC. Seandainya SST sudah memenuhi syarat berarti kolom tersebut layak dipakai dengan ciri-ciri tekanan kolom stabil. Seandainya kolom tersebut memiliki kesiapan pakai dan struktur molekul progesteron dengan rendaman enam dan delapan jam belum pecah maka yang muncul adalah Gambar 2. Sebagai ilutrasi struktur molekul yang telah pecah dan kemampuan kolom yang sudah jenuh perkiraan seperti Gambar 3C. (2) memastikan tekanan dalam 
kolom menjadi naik. Pada keadaan demikian analisis harus dihentikan artinya Eluen Phase Mobile tetap jalan tapi tidak menginjek analit. Kemampuan penangkapan analit oleh fase diam dan terpantau oleh detektor yang memiliki prinsip makin Eluen Phase Mobile polar makin menghasilkan daya tangkap tinggi. Kepolaran dari struktur molekul progesteron memudahkan analit tertangkap oleh kolom (oktadesilsilan (ODS/C18) yang bersifat polar.

Proses pembuatan sediaan mempengaruhi kestabilan suatu zat artinya apabila zat atau analit mudah larut dalam Eluen Phase Mobile sementara tingkat keasaman pelarutnya makin meningkat maka molekul yang dilarutkan akan mudah pecah. Sehingga seluruh pelarut yang dipakai selalu dibuat baru. Disamping itu tingkat keasaman dalam proses pembuatan tersebut sebelum dan sesudah pembuatan selalu dilakukan pemantauan $\mathrm{pH}$. Makin lama pelarut tersebut disimpan tingkat keasaman akan meningkat, apabila pelarut tersebut digunakan maka akan menimbulkan pecahnya molekul bahan aktif obat terebut. Selanjutnya analit juga perlu diperhatikan mengenai kondisi penyimpanan bahan aktifnya. Diketahui bahwa progesteron memiliki kemampuan menarik air dari udara (higroskopis), oleh sebab itu untuk menghindari hal tersebut penyimpanan bahan aktif dilakukan pada desikator. Desikator didalamnya terdapat serbuk yang mengandung bahan penarik air di udara yaitu silica gel. Maka dipastikan karena sistem penyimpanan bahan aktif sudah terjamin dan Eluen Phase Mobile selalu dibuat baru sehingga resiko pecahnya obat tidak terjadi (Lazuardi dan Bambang, 2010).

Kemasan mempengaruhi stabilitas analit dalam Eluen Phase Mobile, oleh sebab itu kemasan yang mampu tertembus sinar matahari harus dihindarkan dalam penelitian ini kemasan selalu dibungkus Alumunium foil. Cara pengemasan dan kondisi lingkungan juga mempengaruhi stabilistas sediaan analit sebagai contoh pengemasan dalam penelitian ini menggunakan vial khusus yang tidak boleh dicuci kembali dengan demikian vial yang baru tersebut diyakini tidak terkontaminasi dengan zat lain. Kondisi pengiriman dari analit vial diatur sedemikian rupa tetap pada suhu 20$25^{\circ} \mathrm{C}$ oleh sebab itu dalam labolatorium selalu disediakan pengukur suhu dan kelembapan udara.

Ketidakstabilan produk obat dapat mengakibatkan terjadinya penurunan sampai dengan hilangnya khasiat obat, obat dapat berubah menjadi toksik atau terjadinya perubahan penampilan sediaan (warna, bau, rasa, konsistensi dan lain-lain) yang akibatnya merugikan bagi si pemakai. Ketidakstabilan suatu sediaan farmasi dapat dideteksi melalui perubahan sifat fisika, kimia serta penampilan dari suatu sediaan farmasi. Besarnya perubahan kimia sediaan farmasi ditentukan dari laju penguraian obat melalui hubungan antara kadar obat dengan waktu, atau berdasarkan derajat degradasi dari suatu obat yang jika dipandang dari segi kimia, stabilitas obat dapat diketahui dari ada atau tidaknya penurunan kadar selama penyimpanan (Ansel, 1989; Lachman et al, 1994).

\section{KESIMPULAN}

Berdasarkan hasil penelitian yang dilakukan dapat disimpulkan bahwa waktu penyimpanan Progesteron dalam larutan Eluen Phase Mobile (EPM) mulai menunjukkan tidak stabil pada waktu 12 jam penyimpanan. 


\section{DAFTAR PUSTAKA}

Aulia, S.S, Sopyan I, Muchtaridi. 2017. Penetapan Kadar Simvastatin Menggunakan Kromatorafi Cair Kinerja Tinggi (KCKT). Jatinagor. Universitas Padjajaran.

Bird, I. M. 1989. High Performance Liquid Chromatography: Principles and Clinical Applications. British Medical Journal. 299:783-787.

Dong, M.W. 2006. Modern HPLC for Practicing Scientist. Canada: A John Wiley and Sons, Inc. Hal. 1-13.

Erkoc, F. U., Ozsar, S., Guven, B., Kalkandelen, G., \& Ugrar, E. (1989). High-Performance Liquid Chromatographic Analysis of Steroid Hormones. Journal of Chromatographic Science. 27(2): 86-90

Gandjar, I. G. dan Rohman, A. 2014. Kimia Farmasi Analisis. Yogyakarta: Pustaka Belajar, hal 323-417

Lazuardi, M. 2010. Biofarmasetik dan Farmakokinetik Klinik Medis Veteriner. Bogor. Ghalia Indonesia.

Lazuardi, M and Bambang H.2017. High-performance liquid chromatography ultravioletphotodiode array detection method for aflatoxin B1 in cattle feed supplements. Veterinary World. 10(8): 932-938
Lazuardi, M and Bambang H. 2018. Technique Separation Phytohormones of Progesterone on CrudeExtract Benalu Duku Leaf By Analytical Column of High Performance Liquid Chromatography. Book Section. Universitas Airlangga: Surabaya

Maliwal, D.P Jain., A. Jain dan V. Patidar. 2009. Determination of Progesterone in Capsules by HighPerformance Liquid Chromatography and UVSpectrophotometry.J

YoungPharm. 1 (4): 371 - 374

Nuriyazizah, A. 2018. Uji Stabilitas Waktu Tambat Kromatogram Clenbuterol Menggunakan Kromatografi Kinerja Tinggi [Skripsi]. Surabaya. Universitas Airlangga

Osol A., Alfonso R.G., Melvin R.G., Stewart C.H. \& Robert E.K. 1980. Remington's pharmaceutical sciences, 16th ed. Mack Publishing Company Easton-Pensivania. 104135: 244-262

Sabdowati, R.A. 2015. Uji Stabilitas Obat Spironolakton Terhadap Perubahan $\mathrm{pH}$ dengan Menggunakan Kromatografi Cair Kinerja Tinggi (KCKT) [Skripsi]. Jakarta. Universitas Islam Negeri Syarif Hidayatullah

Sinreih, M., Zukunft, S., Sosic, I., Cesar, J., Gobec, S., Adamski, J., \& Lanišnik Rizner, T. (2015). Combined Liquid Chromatography-Tandem Mass Spectrometry Analysis of Progesterone Metabolites. PLOS ONE. 10(2) 
Suprianto. 2014. Pengembangan Metode Penetapan Kadar Campuran Pemanis, Pengawet dan Pewarna secara Simultan dalam Sirup Esen dengan Menggunakan Kromatografi Cair Kinerja Tinggi [Skripsi]. Medan. Universitas Sumatera Utara
Susanti, M dan Dachriyanusus. 2014. Kromatografi Cair Kinerja Tinggi. Sumatera Barat: Lembaga Pengembangan Teknologi Informasi dan Komunikasi (LPTIK) Universitas Andalas 